\title{
Estudo clínico e histopatológico da genitália de fêmeas bovinas de corte descartadas após a $3^{a}$ Inseminação Artificial \\ Clinical and histopathologic study of genital system of beef cows slaughtered after third artificial insemination
}

\author{
Dala Vieira Kezen ${ }^{1}$, Neuci Adalton Vinha², Maria Luisa Menezes Schezy ${ }^{3}$
}

\section{Resumo}

Os exames clínicos, macroscópico e histopatológico post-mortem e de biópsia uterina revelaram em vinte e uma fêmea bovinas de corte descartadas após a terceira Inseminação Artificial que a principal causa de infertilidade foi a infecção uterina. Outras condições associadas ao complexo metrite / endometrite, tais como cisto folicular, hipoplasia ovariana, corpo lúteo cístico e cérvix sinuosa também foram observados. Houve correspondência entre todos os métodos de diagnóstico empregados. O exame clínico dos animais permitiu diagnosticar $76,19 \%$ das causas de infertilidade e $71,42 \%$ dos casos de infecção uterina, enquanto o exame macroscópico post-mortem demonstrou $95,23 \%$ dessas causas. Por outro lado, a biópsia uterina demonstrou a mesma acurácia para o diagnóstico de infecção uterina demonstrada no exame histopatológico post-mortem.

Palavras-chave: biópsia uterina, repetição de cio, infertilidade.

\section{Introdução}

Apesar do país apresentar algumas condições relativamente favoráveis, a fertilidade de rebanho bovino brasileiro está muito abaixo dos padrões exigidos pela moderna produtividade pecuária. A baixa produtividade do gado brasileiro é o reflexo direto dos baixos índices de fertilidade e natalidade (Chow et al., 1986), frutos da falta de seleção genética, falhas de manejo, deficiência alimentar e o baixo padrão sanitário.

Doenças ovarianas císticas e hipoplasia ovariana são alterações ovarianas que ocorrem em maior ou menor incidência dependendo da raça ou região e que compromete a função reprodutiva da vaca (Couto e Megale, 1963; Settergren, 1964; Roberts, 1971; Pimentel et al. 1977; Morrow, 1986 e Mcentee, 1990).
A importância do estudo das infecções uterinas, particularmente as do endométrio, prende-se ao fato de serem responsáveis por grande parte dos casos de infertilidade. Está associada ao atraso da involução uterina e ao aumento do número de serviços por concepção em função de um ambiente uterino impróprio para ocorrer o trânsito espermático e/ou a viabilidade e implantação embrionária. A infecção uterina é uma das causas mais comuns de desordens reprodutivas na vaca (Roberts, 1971; Hartigan et al., 1972; Pimentel et al., 1977; Arias, 1985 e Morrow, 1986).

\section{Material e Métodos}

Foram estudadas vinte e uma fêmea bovinas (12 vacas e 9 novilhas) mestiças, com predomínio de sangue das raças zebuínas. Estas foram diagnosticadas não gestantes após realização de três inseminações artificiais no período de primeiro de dezembro de 1991 a trinta e um de março de 1992, provenientes de um rebanho com 868 fêmeas bovinas. Estes animais eram de diversas faixas etárias e criados em regime extensivo. Os dados de cada animal foram anotados em fichas próprias.

O exame clínico e a colheita do material para biópsia uterina foram realizados na fazenda Sagres, município de Carlos Chagas - MG. Os animais foram contidos em brete, identificados e submetidos ao exame ginecológico, constando de inspeção da genitália externa, palpação retal e vaginoscopia. Logo após a palpação retal foi feita a lavagem da vulva com água e sabão, secagem, seguindo-se a introdução da pinça de Yeoman pela via transcervical. O material para biópsia uterina foi coletado de ambos os cornos uterinos, individualmente, na altura da curvatura maior. Cada fragmento obtido foi colocado em frasco individual contendio solução de formol a $10 \%$ e identificado.

\footnotetext{
'Professora Ms. de Fisiopatologia da Reprodução Animal e Inseminação Artificial da Faculdade de Veterinária Plínio Leïte - Rua Visconde do Rio Branco, 137 - Niterói-RJ. CEP 24.020 .000

${ }^{2}$ Professor Titular de Fisiopatologia da Reprodução Animal e Inseminação Artificial da Faculdade de Veterinária da Universidade Federal Fluminense - UFF. Rua Vital Brasil Filho, 64 - Niterói - RJ - CEP 24230-340.

${ }^{3}$ Professora Assistente de Fisiopatologia da Reprodução Animal e Inseminação Artificial Faculdade de Veterinária - UFF.
} 
Os animais foram abatidos aproximadamente 48 horas após a biópsia no matadouro Sola, município de Carlos Chagás - MG. Após o abate, a genitália foi submetida a inspeção post-mortem registrando-se as alterações observadas nas fichas respectivas de cada animal. Em seguida procedeu-se a colheita do material dos ovários, tubas uterina e cornos uterinos, sendo as amostras colocadas em frascos individuais contendo solução de formol a $10 \%$ e identificados.

As amostras foram levadas para o Laboratório de Reprodução Animal da Faculdade de Veterinária da Universidade Federal Fluminense - UFF para serem processadas, coradas pela hematoxilina-eosina para posterior estudo histopatológico.

O estudo e a descrição histopatológica das alterações ovarianas foram feitos com base nas descrições de Settergren (1964), Roberts (1971), Costa (1974), Morrow (1968) e Mcentee (1990).

As endometrites foram classificadas em agudas, subagudas e crônicas em função da intensidade e distribuição das alterações endometriais de acordo com Hartigan et al. (1972), Neves (1976) e Cordeiro et al. (1989).

\section{Resultado}

O exame clínico dos animais analisados permitiu identificar $61,90 \%$ dos casos de infecção uterina e $4.76 \%$, igualmente, dos casos de infecção uterina associada com cervix sinuosa, com hipoplasia ovariana e o cisto folicular. Os demais animais $(23,80 \%)$ não apresentaram qualquer alteração neste tipo de exame.

Das amostras de biópsias uterinas efetivamente analisadas foi observado $100 \%$ de infecção uterina. $\mathrm{Na}$ comparação entre os cornos uterinos de uma mesma vaca foram encontrados $80 \%$ de lesões idênticas e nos $20 \%$ restantes foram obtidos resultados semeIhantes, alterando apenas o grau de endometrite.

No exame macroscópico post mortem a infecção uterina representou o maior número de casos $(66,66 \%)$, seguida por cérvix sinuosa associada a infecção uterina $(4,76 \%)$, hipoplasia ovariana transicional e corpo lúteo cístico associados a infecção uterina (4,76\%) e sem alterações $(4,76 \%)$. (FIG. 1 e 2$)$.

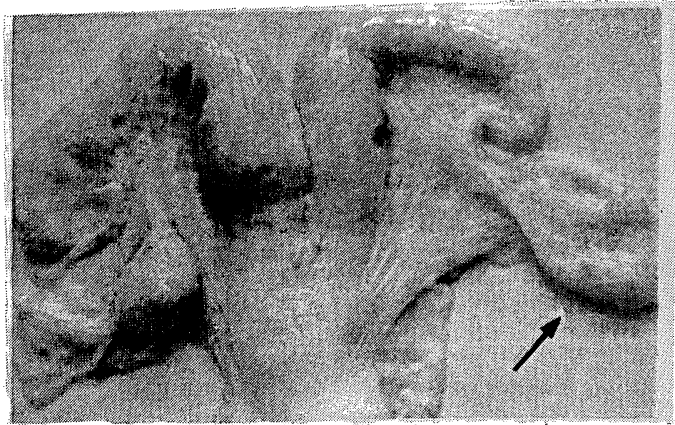

Figura 1

Genitália bovina com hipoplasia ovariana transicionai unilateral e infecção uterina.

\section{Figura 2}

Genitália bovina com cisto folicular unilateral.

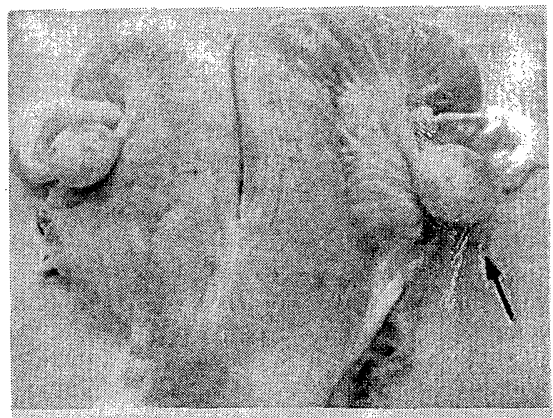

No exame histopatológico foi diagnosticada a endometrite em $100 \%$ dos animais, sendo $76.19 \%$ apresentando somente infecção uterina, $14,28 \%$ apresentando corpo lúteo cístico associado e endometrite, $4,76 \%$ com cisto folicular associado a endometrite e $4,76 \%$ com hipoplasia ovariana transicional e corpo lúteo cístico associados e endometrite. (FIG. 3 e 4).

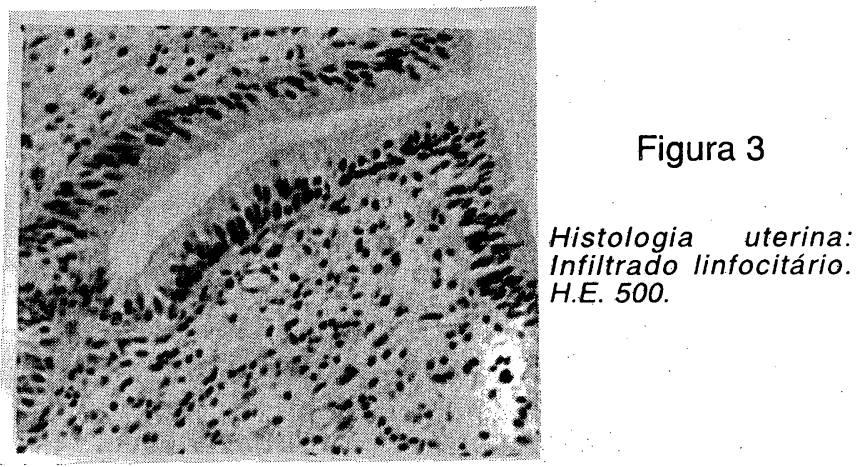

Figura 4

Histologia uterina: Dilatação glandular acentuada focal $e$ fibrose periglandular moderada à grave. H.E. 125.



\section{Discussão}

Houve compatibilidade entre os exames clínicos, post-mortem macro e microscópio no que concerne ao diagnóstico das patologias ovarianas. Os cistos foliculares foram de fácil diagnóstico clínico e estão de acordo com as descrições de Roberts (1971); Morrow (1986); Ahmadijaz et al. (1987) e Mcentee (1990).

Somente após o abate e secção do corpo lúteo foi possível observar a sua cavidade cística. Autores como Mylrea (1962); Tanabe e Almquist (1967) e Costa (1974), afirmam que esta alteração é destituída de importância clínica, o que torna seu diagnóstico sem importância. 
A hipoplasia ovariana foi diagnosticada em todos os exames ao qual o órgão foi submetido, porém esta hipoplasia (transicional) só foi confirmada no exame post-mortem. O exame post-mortem evidenciou lesões semelhantes às descritas anteriormente por Settergren (1964). Esta causa, no entanto, não foi a determinante do abate e o animal apresentava o ovário contra-lateral em funcionamento normal e apresentava ocorrência de um parto em seu histórico.

Do conjunto de resultados obtidos pelos quatro exames ficou evidente que a endometrite é a principal causa de infertilidade, já concluída por outros autores (Simon e Mcnutt, 1957; Hartigan et al., 1972 e Pimentel et al., 1977).

No presente trabalho não houve diferença nos achados entre os cornos uterinos de um mesmo animal e tal observação está de acordo com os autores Manspeaker e Haaland (1983).

Em $62 \%$ dos casos, as endometrites observadas foram diagnosticadas como processos crônicos, em sua maioria com grau moderado, alterações estas que, para Roberts (1971) e Morrow (1986), são lesões recuperáveis. Isto denota a possibilidade de tratamento e recuperação quando se trata de animal de alto valor zootécnico.

O fato marcante neste trabalho foi a correspondência das lesões uterinas na avaliação do material obtido por biópsia, quando comparado com o exame histopatológico post-mortem. Devem-se, por este motivo, enfatizar a importância da técnica de biópsia, como valioso complemento ao diagnóstico, por permitir uma estimativa mais precisa do grau de lesão uterina, quando comparada ao exame clínico isolado, conforme os estudos realizados por Roberts (1971) e Arias (1985).

\section{Conclusão}

Os resultados do presente estudo permitiram concluir que a principal causa de repetições de cio foi a endometrite e que a ocorrência de cisto folicular, hipoplasia ovariana transicional e cérvix sinuosa associada à endometrite agravam o quadro de infertilidade. Conclui-se também que a biópsia de somente um dos cornos uterinos permite um diagnóstico acurado.

Os achados histopatológicos do endométrio de vacas repetidoras de cio sem alterações clínicas, confirmam a importância da biópsia para o diagnóstico de endometrites.

\section{Abstract}

Clinical and histopathologic study of genital system of beef cows slaughtered after third artificial insemination
Twenty-one non-pregnant beef cows after third insemination were submitted to clinical examination of the reproductive tract, including collection of samples for uterine biopsy. Twenty-four hours later they were slaughtered and macroscopic and microscopic examinations of the genital tract were performed. Uterine infections proved to be the major cause of infertility, also associated to others disturbances, such as cystic ovarian disease, ovarian hypoplasia, cystic corpus luteum and sinuosity of the cervix presented in minor cases. Diagnose obtained through rectal palpation of the genital tract, uterine biopsy and postmortem histopathologyc showed good conformity. Through rectal palpation accurately diagnosed $71,42 \%$ of the cows with uterine ifection and $76,19 \%$ of all abnormalities. The post-mortem macroscopic examination of the genital tract found out $95,23 \%$ of the pathologic changes presented. Every samples obtained by uterine biopsy showed to uterine infections, which were later confirmed by the post-mortem histopathologic examination. In conclusion, the main cause of infertility in this group of cows was uterine infections.

Key words: uterine biopsy, repeat-breeder, infertiliy.

\section{Referências Bibliográficas}

AHMADIJAZ, M L, FAHNING. L, ZEMJANIS, R. Treatment and control of. cystic ovarian disease in dairy cattle: a review. Br. Vet. J., London, v.143, n.3, p.226-237, 1987.

ARIAS, G.E.Z. Estudo clínico, bacteriológico e histopatológico de vacas leiteras potadoras de problemas reprodutivos. Niterói, 1985. 58 p. Dissertação (mestrado) - Faculdade de Veterinária, Universidade Federal Fluminense.

CHOW, L.A., AZEVEDO, N.A., CAICEDO, E.T. Indução do estro em bovinos de corte com anestro pós-parto pela administração de $\mathrm{GnRH}$. R. bras. Reprod. Anim., Belo Horizonte, v. 10, n.1, p.37-49, 1986.

CORDEIRO, J.L.F., BARROS, S.S., NEVES, J.P. Avaliação histopatológica do endométrio de vacas leiteiras com catarro genital R. Bras. Reprod. Anim., Belo Horizonte, v.12, n.1, p.7-14, 1989.

COSTA, S.A. Ocorrência de alterações em ovários de vacas azebuadas abatidas em matadouros do Estado de Goiás e Minas Gerais. Belo Horizonte, 1974, 134 p. Dissertação (Mestrado) - Faculdade de Veterinária, Universidade Federal de Minas Gerais.

COUTO, E.S. \& MEGALE, F. Incidência de lesões no sistema genital de vacas azebuadas abatidas em matadouro. Arq. Esc. Vet., Belo Horizonte, v.15, p. 303-309, 1963. 
HARTIGAN, P.J, MURPHY, J.A., NUNN, W.R, GRIFFIN, J.F.T. An investigation into the causes of reproductive failure in dairy cows. Irish Vet. J., Dublin, v.26, n.11, p.225-228, 1972.

MANSPEAKER, J.E. \& HAALAND, M.A. Implementation of uterine biopsy in bovine reproduction: a practioner's diagnostic tool. Vet. Med. Small An. Clin., Edwardsville, v.5, p. 760-766, 1983.

MCENTEE, K. Reproductive pathology of domestic mammals. San Diego: Academic Press, 1990-401 p.

MORROW, D.A. Current Therapy in Theriogenology. Philadelphia: W.B. Saunders, 1986, 1105 p.

MYLREA, P.J. Macroscopic lesions in the genital organs of cows. Austr. Vet. J., Brunswick, v.9, p. 457-461, 1962.

NEVES, J.P. Características clínicas, bacteriológicas e histopatológicas de endometrites pós-puerperais em bovinos. Rio Grande do Sul, 1976.50 p. Dissertação (Mestrado) - Fac. de Vet. de Santa Maria.
PIMENTEL, C.A, DE MEDEIROS, E.L, BENTO, C.L.R, GONÇALVES V.L Endometrites em bovinos de corte. Ocorrência e seu relacionamento com a fertilidade. R. bras. Reprod. Anim., Belo Horizonte, v.1, p. 15-16, 1977.

ROBERTS, SJ. Veterinary Obstetrics and Genital Diseases, 2.ed., Ithaca, New York, S.J. Roberts, 1971. $776 \mathrm{p}$.

SETTERGRREN, N.I. The ovarian morphology in clinical bovine gonadal hypoplasia with some aspects of its endocrine relations. Stockholm, Acta Vet. Scand., 1964. 108 p.

SIMON, J., McNUTTS, S.H. Histopathological alterations of the bovine uterus. II Uterine tissue from cows of low fertility. Am. J. Vet. Res., Chicago, v.4, p.241-245, 1957.

TANABE, T.Y.M. \& ALMQUIST, J.O. Gross genital agnormalities. Pensylvania: Agricultural Experiment Station, 1967. $93 \mathrm{p}$. 